\section{Interweaving Knowledge Systems Through Sustainability Governance}

\author{
João Mourato, Alexandra Bussler and \\ Fronika de Wit \\ Institute of Social Sciences, University of Lisbon, \\ Lisbon, Portugal
}

\section{Synonyms}

Knowledge Systems; Knowledge Brokerage; Sustainability Governance; K4DP; KM4Dev; SDGs; UN; UN Agenda 2030; UNDP

\section{Definitions}

In the UN (United Nations) and its agencies, a knowledge broker is defined as a "builder of capacities and facilitator of exchanges in the global development debate" in order to realize development outcomes (UNDP 2014). The UNDP (United Nations Development Programme) emphasizes its own role as knowledge broker connecting solutions seekers with providers and transmitting existing practical knowledge and expertise from practitioners, as laid down in its knowledge management strategy framework 2014-2017 (UNDP 2014). The main contributions of knowledge brokerage are seen as: (i). identifying, capturing, disseminating, and applying lessons learned from past projects and initiatives; ii. strengthening knowledge exchange and networking, through corporate social networking and thematic communities of practice; iii. fostering openness and public engagement through blogging, public online dialogs, consultations, and events; and iv. embedding knowledge management into talent management, HR processes, including training (UNDP 2014).

This definition coincides with the literature on knowledge governance, where knowledge brokerage is generally framed as facilitating the creation, transfer, and use of knowledge across different knowledge systems. It includes the action of intermediating knowledge, facilitating collaboration and interaction, working both in the public as well as in the private domain. In the UN Agenda 2030 (United Nations (UN) Transforming Our World: The 2030 Agenda for Sustainable Development), in its sustainable development goal (SDG) 17, partnerships towards sustainability are understood as multistakeholder initiatives on a voluntary basis where different actors, governmental, nongovernmental, private sector, or civil society join in order to leverage and implement global and local pathways towards sustainability. In the specific context of SDG 17, knowledge governance in general and knowledge brokerage in particular play a crucial role as links and bridges between the different knowledge systems necessary for managing the complexity of a transition towards sustainability. 


\section{Introduction}

The year 2020 will go down in history as the global breakout year of the Covid-19 virus. With its devastating impacts yet to be fully determined, the pandemic's anthropogenic origins, reach, public, and political response are a stark reminder of the challenges the implementation of the UN Agenda 2030 and its 17 sustainable development goals (SDGs) will face. At first, the urgency and immediacy of the Covid-19 crisis may fog this comparison. However, a striking resemblance becomes apparent when taking into account the pandemic's global nature, associated geopolitical strife, scrambled initial institutional action, dynamic of (mis)information flows, and uneven geographical and socioeconomic implications.

Concerning knowledge, a clear dichotomy emerged during Covid-19. On the one hand, a collaborative race for solutions began in terms of treatment, containment, and prevention. From epidemiologists, physicians to social psychologists, from local nurses to the World Health Organization, from national heads of state to mayors and civil society, Covid-19 mobilized joint working at different levels, sectors, and between a widely diverse array of actors. On the other hand, it also illustrated the speed in which fake facts spread in the age of post-truth. This highlighted the dangers of knowledge politicization, with its use primarily tuned for political combat rather than socially beneficial purposes.

Multiple lessons can be taken from the outset of the pandemic to inform the implementation of the UN Agenda 2030 and the SDGs: the need to reorganize political priorities in face of a perceived emergency and to work collaboratively at multiple levels, as well as the relevance of an adequate knowledge governance framework. The political perception of the urgency of the UN Agenda 2030's objectives is an ongoing advocacy battle amidst conflicting interests with no end in sight. The latter two sit at the heart of SDG 17 - the last but not least of the SDGs.

Transversal in its nature, SDG17 strives for global partnerships for sustainable development. It guarantees the pursuit of all other SDGs, as decades of international governance efforts have shown that governments alone cannot ensure a transition to sustainability even if they are genuinely committed to it (Ostrom 2010). SDG17 aims at multistakeholder partnerships that "mobilize and share knowledge, expertise, technology and financial resources, to support the achievement of the sustainable development goals" (SDG Knowledge Platform 2020).

Sharing knowledge among a diverse range of stakeholders is easier said than done since it involves dealing with multiple knowledge systems. However, in most cases their governance relies solely on one type of knowledge: that of the managers or decision-makers (Tengö et al. 2014). Thus, there is a growing advocacy for a more inclusive knowledge base when designing policy solutions to address the complexity and uncertainty of a transition to sustainability. Complementarities across knowledge systems, such as local knowledge and scientific knowledge, make for improved sustainability governance at multiple scales (Tengö et al. 2017; Clarke et al. 2013).

The recognition of the existence of multiple knowledge systems by itself does not necessarily lead to a knowledge governance towards sustainability. Often, the communicational distance between different knowledge systems and, in some cases, within a specific knowledge system itself, ask for a further task: knowledge brokerage. Focused on informing policy development and enhancing decision-making, knowledge brokers aim to identify who needs to be engaged and how, sources of information to be used, and steward long-term professional and institutional relationships (Michaels 2009; Rathwell et al. 2015). In sum, knowledge brokerage fruitfully connects diverse knowledge systems towards a transition for sustainability.

This chapter expands on the fundamental importance of knowledge brokerage for SDG 17 illustrating its potential role and critically debating its impacts and limits to action. Part I introduces the concept of knowledge governance as the contextual framework where the debate about knowledge systems and their role in a transition to sustainability takes place. Part II zooms in on knowledge brokerage as an essential element of knowledge governance. It breaks down 
its conceptual outline and critically reviews its key facilitating and limiting factors. The chapter concludes with a set of key points to further the knowledge brokerage debate within the context of the UN Agenda 2030 and all of its 17 SDGs.

\section{Knowledge Governance Towards Sustainability}

Our common future, the pivotal Brundtland Commission Report (WCED 1987), outlined the unavoidable multidimensional and multilevel nature of a transition towards sustainability. This transition's underlying complexity and uncertainty have increasingly been acknowledged. Contrastingly, traditional policy planning and implementation have not been able to properly leverage this transition. This stresses the need for better policy solutions to anticipate and adjust to the changes, surprises, and disruptions emerging alongside this sustainability transition (Quay 2010).

Conventional systems of government have struggled to resolve sustainability problems (Clarke et al. 2013). This reflects how different societal actors have very different views on sustainability and how to achieve it (Shiroyama et al. 2012). Their political ideologies, values, education, professional training, and work- and nonwork-related experience shape how they define and understand public problems (Kraft 2017). The societal dilemmas associated with sustainability are complex because their impacts are primarily visible in the future and not in the present (Van Lange et al. 2018). As these authors explain, uncertainty leads to heuristic thinking. Individuals then naturally lean towards personal or local problems, rather than abstract global issues - and political leaders follow suit. This perspective is a fertile ground for what Doherty (2015) calls "knowledge wars," a post-truth-era reality when "alternative facts" replace actual facts, and feelings have more weight than evidence (McIntyre 2018).

The defining challenges of the sustainability transition can be subsumed by: (i) its uncertain and abstract nature, (ii) a wide range of actors involved, and (iii) the difficulty to ensure their accountability, manage their conflicting interests, and outline effective courses of action (Kemp et al. 2005). Against this backdrop, governance for sustainability becomes an unavoidable need.

Shiroyama et al. (2012, p. 46) define governance for sustainability as "formal and informal networks/interactions among actors, and systems composed by them, that influence sustainability by integrating its various dimensions." These authors go on to state that "governance for sustainability asks for knowledge integration as a means to deal with multiple dimensions of sustainability and uncertainty" (Shiroyama et al. 2012, p. 46). The latter requires "fresh thinking about the mechanisms that might generate and inspire constructive co-knowing to advance decision making" (Michaels 2009, p. 995).

Accordingly, the sustainability debate has increasingly focused on the issue of knowledge. What knowledge underpins the very concept of sustainability and its pursuit? Who creates it? Who regulates it? What are the checks and balances in place to manage the pluralistic understanding of a world where multiple knowledge systems often clash? In other words, what are the knowledge politics steering a wider transition towards sustainability?

Critics tend to highlight an inadequate integration of the variety of existing knowledge systems in current governance for sustainability (Clarke et al. 2013). Knowledge resides within various academic disciplines and diverse actors across society. However, the way it is currently available and used only makes "a limited contribution to sustainability policy and governance" (EEA 2019 , p. 402). In other words, defining and pursuing transition goals and pathways require information about the interests and preferences of the different groups involved and their visions for the future (EEA 2019). However, there has been a "broader failure to capture the complexity of voices, interests and values" (Clarke et al. 2013, p. 88) underpinning such a transition.

These limitations have fueled a growing call for enhanced knowledge governance for sustainability. This refers to the deployment of governance mechanisms to influence knowledge 
processes, such as sharing, retaining, and creating knowledge (Foss 2007). In face of the aforementioned criticisms, a key challenge in informing a transition towards sustainability is the design of the processes that optimize the knowledge transfer between where it sits and where it is needed (cf. Tábara and Chabay 2013). To do so, the dynamics of knowledge-based interactions need to be broken down. It is necessary to take into account the characteristics of the type of knowledge in question, the actors involved, the relationship between these actors, and the outcomes of the knowledgesharing process (Foss and Michailova 2009).

A good starting point to explore the challenges of knowledge governance for sustainability is the relationship between science and policy. Science is recognized as such an authoritative mechanism of legitimation that policy debates more often than not are focused on technical questions and the issue of values gets somewhat sidetracked (Michaels 2009).

The established almost linear model of transmission of science into policy has been growingly criticized over the last 20 years (e.g., Clarke et al. 2013; Foss and Michailova 2009). Critics claim that successful policy development rather requires the involvement of diverse stakeholders and the integration of their respective knowledge and experiences. Knowledge is referred to as the way people interpret, understand, and apply meaning to the world and to their experiences (Clarke et al. 2013; Hulme 2009). In this context, conventional scientific knowledge is usually contrasted with other types of knowledge, such as local or traditional knowledge. The challenge related to the latter is however how to develop useful, relevant, and credible information for policymakers (Brown 2009).

Hulme (2009) systematizes this debate with three science policy models: (i) the decisionist model (goals set by politicians); (ii) the technocratic model (goals set by science); and (iii) the coproduction model (joint scientific and nonscientific considerations). The latter promotes improved knowledge governance for sustainability, as different forms of knowledge are seen to bring valuable perspectives into a colearning process (Brown 2009). A similar reasoning extends to the technocratic model: the science necessary to address a transition towards sustainability differs to a considerable degree in structure, methods, and content from traditional disciplinary science. Progress in increasing the impact of science will require a more problem-driven and interdisciplinary research approach.

Despite sound reasons calling for the integration of nonscientific knowledge into policy design and decision-making processes, its practical implications have to be considered carefully. For one, it has to be decided what constitutes legitimate knowledge, who is entitled to speak, and how open should science be to take in other knowledge systems (Jasanoff 1996). On the other hand, specific institutions and processes that enable different knowledge systems to influence governance processes have to be developed (Clarke et al. 2013).

These knowledge systems comprise the agents, practices, and institutions that organize the internal production, transfer and use of knowledge. Building on the assumption that legitimacy, credibility, and availability are fundamental for knowledge's effective use in efforts toward sustainability, the key question remains how to ensure that all relevant knowledge becomes usable.

The diversity and complexity of the sustainability transition require to take into account dynamic and multifaceted forms of knowledge, ranging from scientific, technical to local and tacit knowledge (Feagan et al. 2019). Therefore, the attention falls on the processes of linking and bridging between different knowledge systems (Fig. 1). According to Tengö et al. (2014), a "cross-fertilization among a diversity of knowledge systems" has the power to generate new evidence, to enhance the interpretation capacity, and subsequently to find answers, promote changes and innovate. But how does this specific knowledge reach the destination where it is needed? For instance, how can specific local knowledge reach and impact decision-making processes in the required form and timeliness so that informed policies can be developed? Here enters the fundamental role of knowledge brokerage as a bridging platform, crucial to paving the 


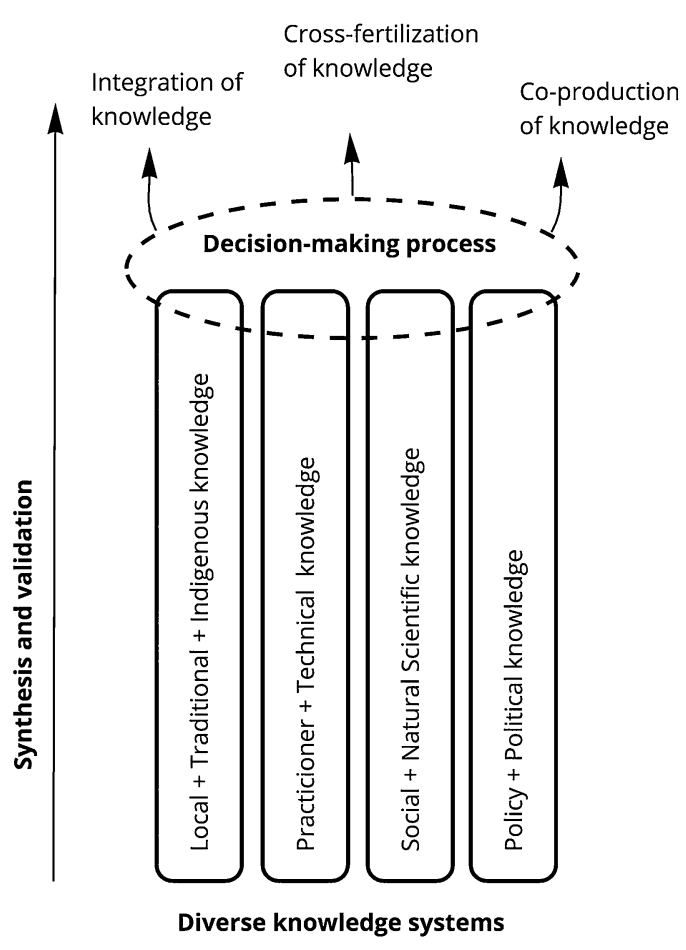

Interweaving Knowledge Systems Through Sustainability Governance, Fig. 1 Linking across diverse knowledge systems. (Adapted from Tengö et al. 2014, p. 582)

way towards sustainability (Tábara and Chabay 2013).

\section{Knowledge Brokerage: The Missing Piece of the Puzzle?}

"Brokered knowledge is knowledge made more robust, more accountable, more usable; knowledge that 'serves locally' at a given time; knowledge that has been de-and reassembled" (Meyer 2010, p. 123).

Knowledge brokerage, the concept of facilitating the sharing and transfer of knowledge across knowledge systems, has become an important factor in the current sustainability debate (Michaels 2009). Different bodies of literature have come to study knowledge brokerage in relation to diverse subareas of sustainability, from cooperation for sustainable development to policy development and decision-making towards sustainability (e.g., Tengö et al. 2014, 2017; Cummings et al. 2019).

First and foremost, knowledge brokerage serves to diminish an information deficit between producer and user of knowledge, resulting from particular unfulfilled information needs or when useful information exists but the potential user does not know about it (McNie 2007). As Cummings et al. (2019, p. 785) put it, knowledge brokerage can be characterized by its functions: "adapting, translating, connecting, acting as an intermediary, match-making, convening of networks and professional learning, connecting supply and demand for knowledge, catalysing and facilitating." Independent from its form, knowledge brokerage is a means to an end: improved decision-making (Michaels 2009).

Accordingly, and broadly speaking, a knowledge broker can be defined as an individual, institution, or organization that has access and moves across different knowledge systems that are embedded in persons, positions, or groups (Ward et al. 2009). In other words, knowledge brokers intermediate and facilitate the collaboration and interaction across different, often unrelated, knowledge systems, in both the public and private domain. They help the creation, dissemination, and use of knowledge across those systems (cf. Sheate and Partidário 2010; Stovel et al. 2011; Meyer 2010; Tengö et al. 2017). According to Reinecke (2015), knowledge brokers' main actions are: identifying and localizing knowledge; coordinating and networking; compiling and translating; building capacity; analyzing, evaluating, and developing policy; and finally consulting.

In addition, Michaels (2009) identifies six different strategies that can be applied in different knowledge brokerage situations. These are: informing; consulting; matchmaking; engaging; collaborating; and building adaptive capacity. The order reflects the increasing level of intensity of relationship building (Table 1). The left column summarizes the six different strategies, the middle column explains their main focus of action, and the right column gives specific examples for each brokerage strategy.

For instance, in the consulting strategy a broker is usually approached by a knowledge seeker who 
Interweaving Knowledge Systems Through Sustainability Governance, Table 1 Knowledge brokerage strategies, techniques and practical examples (adapted from Michaels 2009, p. 1000)

\begin{tabular}{|c|c|c|c|}
\hline Strategy & Description & $\begin{array}{l}\text { Examples of brokerage } \\
\text { techniques }\end{array}$ & $\begin{array}{l}\text { Examples of real-world } \\
\text { application }\end{array}$ \\
\hline Informing & Disseminate content & $\begin{array}{l}\text { Fact sheet; booklet; } \\
\text { website }\end{array}$ & $\begin{array}{l}\text { Publicly available online/physical } \\
\text { reports on specific subjects }\end{array}$ \\
\hline Consulting & $\begin{array}{l}\text { Consulting a knowledge seeker on } \\
\text { a specific problem or engage a } \\
\text { third party to do so }\end{array}$ & $\begin{array}{l}\text { Policy briefing; } \\
\text { meetings; solicited } \\
\text { consultations }\end{array}$ & $\begin{array}{l}\text { Municipalities receive policy } \\
\text { consulting for climate action } \\
\text { policy development }\end{array}$ \\
\hline Matchmaking & $\begin{array}{l}\text { Find out the type of needed } \\
\text { expertise, where it is located, and } \\
\text { the best way to bridge across } \\
\text { seeker and holder of knowledge }\end{array}$ & $\begin{array}{l}\text { Introduce parties who } \\
\text { otherwise would not } \\
\text { know of each other }\end{array}$ & $\begin{array}{l}\text { An overarching organization } \\
\text { builds on a broad knowledge } \\
\text { network. It facilitates knowledge- } \\
\text { seeking policymakers the } \\
\text { connection to individuals of the } \\
\text { organization with the required } \\
\text { expertise }\end{array}$ \\
\hline Engaging & $\begin{array}{l}\text { Brokers take on the role of } \\
\text { facilitator and liaise across } \\
\text { different parties: the one with the } \\
\text { problem and starting a process to } \\
\text { solve it, and the other parties } \\
\text { holding and delivering knowledge } \\
\text { when needed }\end{array}$ & $\begin{array}{l}\text { Technical committees; } \\
\text { workshops; focus groups }\end{array}$ & $\begin{array}{l}\text { A national government asks a } \\
\text { technical committee to prepare a } \\
\text { report for a specific topic (e.g., } \\
\text { carbon neutrality pathways) }\end{array}$ \\
\hline Collaborating & $\begin{array}{l}\text { Leveraging a joint decision } \\
\text { process where actors frame their } \\
\text { interaction and negotiate how a } \\
\text { specific problem is addressed }\end{array}$ & Jointagreements & $\begin{array}{l}\text { A multi-stakeholder workshop on } \\
\text { a specific topic including holders } \\
\text { of different knowledge systems } \\
\text { develops a final document that } \\
\text { informs decision-making }\end{array}$ \\
\hline $\begin{array}{l}\text { Building } \\
\text { capacity }\end{array}$ & $\begin{array}{l}\text { Taking the collaborative approach } \\
\text { further: } 1 \text {. leveraging a joint } \\
\text { decision process where actors } \\
\text { frame their interaction and } \\
\text { negotiate how to address the } \\
\text { multiple dimensions of a problem; } \\
\text { 2. identifying what can be learned } \\
\text { from this process and applied to } \\
\text { future related situations }\end{array}$ & $\begin{array}{l}\text { Coproduction of } \\
\text { knowledge; } \\
\text { comanagement of a } \\
\text { research-policy project; } \\
\text { training actions }\end{array}$ & $\begin{array}{l}\text { Various stakeholders } 1 . \text { negotiate } \\
\text { the rules of a collaborative } \\
\text { process; } 2 \text {. develop a joint } \\
\text { agreement to address a current } \\
\text { issue and frame future learning } \\
\text { and monitoring; the latter can be } \\
\text { updated as new knowledge } \\
\text { becomes available }\end{array}$ \\
\hline
\end{tabular}

is accountable for a specific problem. The broker's main task is to identify where needed knowledge sits and bridge across knowledge holder and seeker. This can be done formally or informally, via on-site or distant formats. An example would be that a municipality, as the decision-making authority, commissions a knowledge broker for consulting on a specific topic, such as climate action policy development. But it may also be the case that the same municipality wishes to develop a participatory approach to support their climate action policy development and build on knowledge brokerage to engage local key stakeholders and leverage the cocreation of such policy that finally capacitates the municipality's technical staff. In other words, all these strategies (Table 1) are not mutually exclusive, as it is often the case that a knowledge brokerage process may overlap two or more strategies. Notwithstanding, each strategy can work on its own with a very specific mission and target audience.

The practice of sustainability-related knowledge brokerage is expanding rapidly. From local adaptation and mitigation to climate change (e.g., Mourato et al. 2018; Porter et al. 2015), biodiversity policies in ecological systems (e.g., Reinecke 2015) to wider environmental governance (e.g., Bäckstrand 2003), knowledge brokerage emerges 


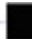

Interweaving Knowledge Systems Through Sustainability Governance, Fig. 2 Simple knowledge brokerage relationships. (Adapted from Stovel et al. 2011, p. 21327)

in a growing number of policy areas. In this sense, the implementation of the SDGs is no exception. As Cummings et al. (2019) explain, KM4Dev, founded by the International Development Research Council (IDRC) in Canada in 2001, is a community of practice of international development experts. As a global network, KM4Dev (Knowledge Management for Development) takes on the role of a cognitive bridge across development agents, international development institutions, and governments. Similarly, the Austrian K4DP (Knowledge for Development Partnership) developed in 2017 the Agenda Knowledge for Development, consisting of 13 knowledge development goals aiming to complement the SDGs from a knowledge perspective (cf. Brandner and Cummings 2017).

\section{How Does Knowledge Brokerage Work?}

Following a structural approach (cf. Wasserman and Faust 1994), there are different forms of knowledge brokerage with respect to their complexity (i.e., Figs. 2 and 3). Below, knowledge systems or knowledge holders are represented as blue dots, the knowledge broker as a black dot, and the connections between the different actors in the network are shown as blue lines.

The most straightforward and simple form of brokerage is the one where the knowledge broker links two otherwise unconnected knowledge systems, acting as a bridge or intermediator (Fig. 2). Figure 3 shows two more complex stylized depictions of the knowledge brokerage configurations. They vary depending on the degree of complexity of relations between knowledge holders or systems, and the knowledge broker itself. In the network on the left, the different knowledge holders do not interact with each other, yet become interlinked via the broker. On the right, some actors are interlinked priorly, representing cohesive knowledge communities, while others only become interlinked via the knowledge broker. These structural variations represent how differently types of knowledge can flow among different actors of the network, and how close or distant they are from each other and/or from the knowledge broker. Furthermore, one can distinguish between middle-man brokers and catalyst brokers; while the former rather facilitates exchange across established relationships and the latter focuses on generating new relationships and bridges across knowledge holders (cf. Stovel et al. 2011).

\section{Where Does Knowledge Brokerage Take Place?}

Nowadays, knowledge brokerage takes place at multiple interfaces that bridge existing knowledge systems. However, at the time of its conceptual outline this was not the case. Sheate and Partidário (2010) pin the conceptual origins of knowledge brokerage in an attempt to methodologically bridge the gap between expert and experiential knowledge in order to foster "evidence-based" community development.

For effect, the science-policy interface has dominated the knowledge brokerage debate so far. It initially focused on the translation of scientific knowledge into policy-relevant knowledge and, to a lesser extent, of policy knowledge into science-relevant knowledge (Van den Hove 2007). As sustainability policies are developed facing controversial scientific findings and complex relationships, combined with uneven or scarce information, the importance of science knowledge for policymaking has been increasing since it has repeatedly been argued that it improves policies or regulatory decisions (Sheate and Partidário 2010; Holmes and Clark 2008; Bielak et al. 2008). Knowledge brokerage in this context aims at enabling decision-makers to acquire and value expert knowledge that otherwise would not have been incorporated into decision-making (Michaels 2009). At its most effective, the information flow is bidirectional (Cash and Moser 2000).

However, there is an increasing perception that assessing sustainability as a policy field ultimately needs to draw on multiple knowledge systems (Sarewitz 2004; Bocking 2004). Therefore, knowledge brokerage is moving beyond the strict 


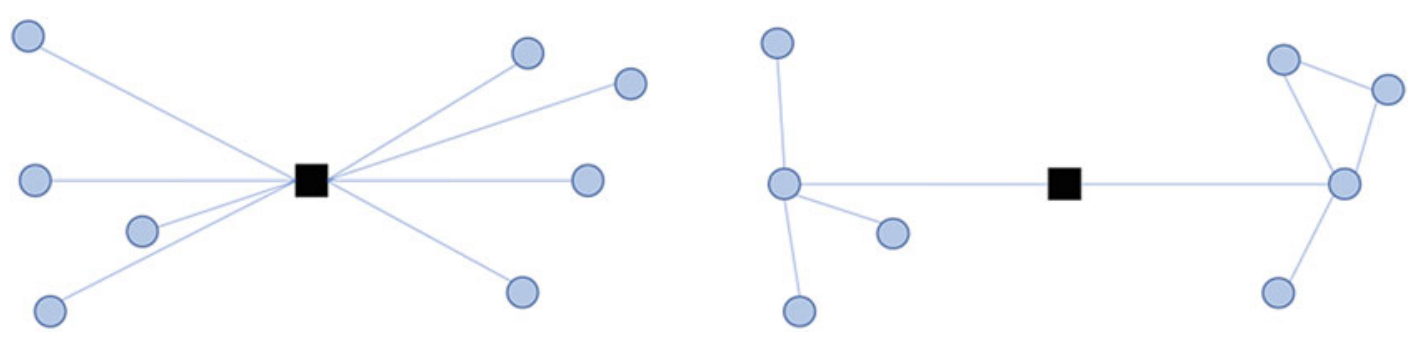

Interweaving Knowledge Systems Through Sustainability Governance, Fig. 3 More complex knowledge brokerage relationships. (Adapted from Stovel et al. 2011, p. 21327)

\section{Interweaving}

Through Sustainability

Governance,

Fig. 4 Knowledge

brokerage as knowledge

systems' interface (authors'

elaboration)
Knowledge Systems

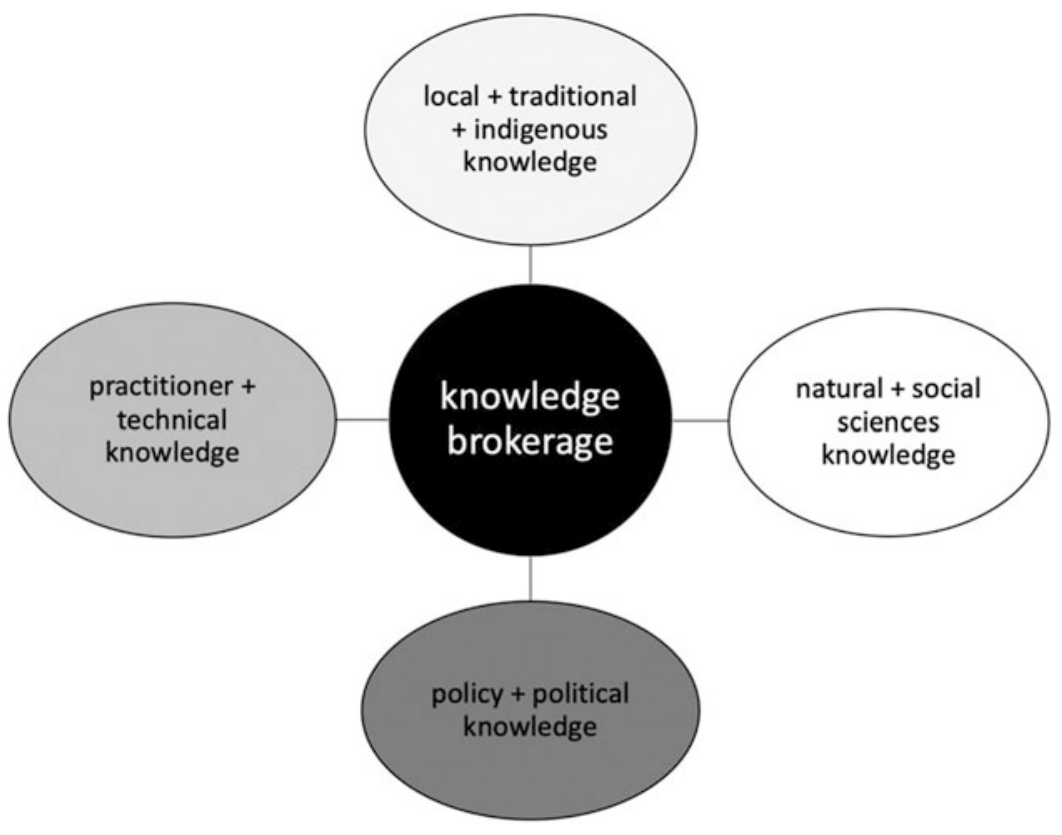

science-policy link to include a diversity of knowledge and intelligences. This results in a more dialogical approach to knowledge dissemination through various potential user groups and the overall institutionalization of science-policy interfaces in a democratic context (Van den Hove 2007). In sum, it is neither in science lay knowledge or policy alone that answers to the increasingly complex challenges of a transition towards sustainability can be found. A crosscutting knowledge bridging involving "[...]different ways of knowing with different degrees of rationality ranging from scientific and philosophical to more intuitive and innate[...]" (Blackmore 2007, pp. 512-513) is more appropriate. Figure 4 shows how various knowledge systems are made up of different actors with their specific ways of knowing and doing and how they are interconnected via the knowledge broker.

For one, science does not necessarily stand in the middle of this bridging process - rather, it can be seen as a pillar of the whole knowledge-sharing framework. To this effect, an increasing interdisciplinary scholarship focuses on how different knowledge systems can be brought together in order to enhance governance towards sustainability (e.g., Fazey et al. 2014; Gómez-Baggethun et al. 2013; Rathwell et al. 2015), or how to bridge the scientific and civil society knowledge systems via public participation or knowledge cocreation (cf. Weiss et al. 2013; Riedlinger and Berkes 2001; Armitage et al. 2011). All in all, there is 
currently a general shift away from a normative view on the integration of knowledge from different knowledge systems towards more egalitarian approaches (Rathwell et al. 2015) of knowledge valuing and sharing amidst different knowledge systems. The latter informs what Tengö et al. (2014) call an interweavable "multiple evidence base" from different knowledge systems to solve sustainability problems.

\section{Challenges, Barriers, and Facilitators of Knowledge Brokerage}

The embedding of different knowledge systems into an overarching knowledge system allows for the fixing, learning, and application of knowledge over long periods of time. In other words, the formal and informal "institutionalization" of knowledge enables long-lasting relationships of trust and respect that can ultimately turn into multistakeholder partnerships for sustainability action (cf. Tengö et al. 2017; Michaels 2005). Ideally, this knowledge infrastructure represents an actor-network spanning across sectors, scales, and communities of practice. However, and despite the importance attributed to knowledge brokerage in facilitating a transition towards sustainability, there are several challenges that hinder its practice.

Firstly, Reinecke (2015) proposes to analyze knowledge brokerage according to three principles: credibility, saliency, and legitimacy. The challenge of credibility concerns the trustworthiness and technical/scientific accuracy of the information conveyed by the broker, since these are central qualities to knowledge (Reinecke 2015). This regards the knowledge broker's impact on the knowledge transfer process (cf. Michaels 2009). Does the broker's interference lead to a partial knowledge loss or transformation of it, and if so, to which extent? Saliency refers to how relevant the knowledge is to the final user. The challenge is for the broker to identify which knowledge is exactly needed so that it becomes actionable in practice (cf. Cash et al. 2003; Reinecke 2015). Legitimacy concerns the degree to which diverse values and views are integrated in a knowledge production process to guarantee unbiasedness and fairness. This concerns how different knowledge systems that do not follow similar rules and practices are mobilized and integrated. For instance, how to bridge indigenous and scientific knowledge to inform policymaking if the starting point mirrors often diametrically opposed worldviews? Similarly, how to make sure that the initial holder of knowledge is able to follow through the knowledge bridging process? The challenge lies for multistakeholder approaches to mobilize, translate, negotiate, and integrate knowledge across these invisible boundaries towards final application (cf. Tengö et al. 2017; Riedlinger and Berkes 2001; Cash et al. 2003; Weiss et al. 2013).

Secondly, a knowledge broker's action is challenged by the ties inevitably developed with all actors throughout the process. This becomes particularly complex when bridging across conflicting knowledge systems. A knowledge broker risks being drafted to one side, even perhaps to the most powerful knowledge holder (Stovel et al. 2011), which could undermine the value and skew the outcome of the knowledge brokerage process.

Finally, there is the question of the outcome of knowledge brokerage. Does the bridging or conveying of relevant knowledge ultimately lead to its inclusion into the decision-making process (Michaels 2009)? This refers to the risk of brokered knowledge not meeting the final needs for its application, finding political opposition to its use, or that the established ties across knowledge systems vanish once the broker disappears. The challenge lies in facilitating long-lasting knowledge relationships that outlive the brokerage process and create a true learning legacy that informs desired pathways towards sustainability.

All these challenges revolve around the type of communication that has to be established and how actors have to be engaged (e.g., Juhász and Lengyel 2018). The literature hints at some solutions to overcome these dilemmas. For one, the risk of the broker's personal impact on the information and its inadequacy for final use may be mitigated by both involving the final knowledge users early in the process (e.g., Jull et al. 2017; Menny et al. 2018) as well as thriving for external validation by renowned experts (Reinecke 2015). 
Furthermore, when brokerage functions are embedded into existing organizations, the level of trust in-between different knowledge systems increases, creating a sort of neutrality zone (Stovel et al. 2011). This institutionalization of knowledge brokerage is fundamental to allow for a collaborative exchange where the integrity of each knowledge system is respected (Tengö et al. 2017).

\section{Concluding Remarks}

The implementation of the UN Agenda 2030 and its 17 SDGs will depend on a structural reorganization of political priorities worldwide. Recent decades of governance efforts have shown that governments alone cannot ensure a transition towards sustainability. In face of the rise of posttruth politics and the challenges of pursuing global climate action efforts, the UN Agenda 2030 plays a pivotal role. It must strive to push the wider transition towards sustainability back on track politically, and secure its implementation on the ground. SDG 17, with its aim to create global partnerships for sustainable development, plays a central role in this process. It is transversal to the pursuit of all other SDGs.

However, SDG 17 faces an uphill battle, since it is a crucial knowledge governance endeavor. Here is where the decisive challenges lie: First, the mere existence of a knowledge governance framework does not automatically imply that knowledge flows from where it is produced to where it is needed. Second, conflicting knowledge systems are a source of innovation and policy learning, but at the same time they can inflict structural damage, or even bring to a halt, policy development. Third, knowledge governance is highly exposed to political pressures, thus it is a challenge in itself to secure desired levels of legitimacy, transparency, and accountability in knowledge production, transfer, and use.

This is the arena for knowledge brokerage, increasingly perceived as a fundamental process in informing decision-making for sustainability. At first sight, it focuses on bridging between where knowledge sits and where it is needed, identifying sources and building long-lasting relationships. However, there is another crucial role for knowledge brokerage. It concerns the management of conflicts of interest among different sustainability stakeholders, of conflicts between objectives and implementation strategies that hail from different development goals, and conflicts between different knowledge systems and their agendas.

The potential contradictions that will surface from the UN Agenda 2030 implementation cannot be overlooked. Knowledge brokerage plays a potentially crucial role in ensuring that the SDGs forward a just transition towards sustainability. The challenge lies in not solely promoting such transition, but also to assure its saliency, credibility, legitimacy, and justice. To pursue the latter, acknowledging the role of diverse values and views from different kinds of expertise (e.g., science vs. practice) in the knowledge production process is paramount. A pluralistic approach, embracing multiple voices, such as indigenous or local knowledge, needs to be further valued and strengthened in order to promote knowledge unbiasedness and an overall more democratic process. An inclusive and democratic knowledge base when it comes to designing policy solutions for a transition to sustainability is the make or break factor for long-lasting partnerships and a key determinant of the impact of the UN Agenda 2030 .

\section{Cross-References}

Cross-Sector Partnerships: Role Toward Achieving the UN Sustainable Development Goals

- Global Partnership in the Service Industries for Sustainable Development

- International Governance of Global Commons in the Context of SDG 17

Acknowledgments João MoraisMourato acknowledges the financial support of the Portuguese Fundacão para a Ciência e a Tecnologia (FCT) through the FCT science employment contract at ICS ULisboa - ref. N. ${ }^{\circ} 7 / 2019$ / NT-GH-01 
Alexandra Bussler acknowledges the financial support of the Portuguese Fundacão para a Ciência e a Tecnologia (FCT) through the doctoral scholarship with ICS ULisboa - ref. SFRH/BD/143942/2019

Fronika de Wit acknowledges the financial support of the Portuguese Fundacão para a Ciência e a Tecnologia (FCT) through the doctoral scholarship with ICS ULisboa - ref. SFRH/BD/129274/2017

\section{References}

Armitage D, Berkes F, Dale A et al (2011) Co-management and the co-production of knowledge: learning to adapt in Canada's Arctic. Glob Environ Chang. https://doi. org/10.1016/j.gloenvcha.2011.04.006

Bäckstrand K (2003) Civic science for sustainability: reframing the role of experts, policy-makers and citizens in environmental governance. Glob Environ Polit. https://doi.org/10.1162/152638003322757916

Bielak AT, Campbell A, Pope S, et al (2008) From science communication to knowledge brokering: the shift from "science push" to "policy pull." In: Communicating science in social contexts: new models, new practices. New York, Springer Science + Business Media B.V.

Blackmore C (2007) What kinds of knowledge, knowing and learning are required for addressing resource dilemmas?: a theoretical overview. Environ Sci Pol. https://doi.org/10.1016/j.envsci.2007.02.007

Bocking, S. (2004). Nature's Experts: Science, Politics, and the Environment. Rutgers University Press, New Brunswick, New Jersey; London

Brandner A, Cummings S (2017) Agenda Knowledge for Development: strengthening Agenda 2030 and the Sustainable Development Goals. Austria

Brown K (2009) Human development and environmental governance: A reality check. In: Adger WN, Jordan A (eds) Governing Sustainability. Cambridge University Press, Cambridge, pp 32-51

Cash DW, Moser SC (2000) Linking global and local scales: designing dynamic assessment and management processes. Glob Environ Chang. https://doi.org/ 10.1016/S0959-3780(00)00017-0

Cash DW, Clark WC, Alcock F et al (2003) Knowledge systems for sustainable development. Proc Natl Acad Sci U S A. https://doi.org/10.1073/pnas. 1231332100

Clarke B, Stocker L, Coffey B, Leith P, Harvey N, Baldwin C, ... \& Haward, M. (2013). Enhancing the knowledge-governance interface: Coasts, climate and collaboration. Ocean Coast Manag 86:88-99

Cummings S, Kiwanuka S, Gillman H, Regeer B (2019) The future of knowledge brokering: perspectives from a generational framework of knowledge management for international development. Inf Dev. https://doi.org/ $10.1177 / 0266666918800174$

Doherty P (2015) The knowledge wars. Melbourne University Press, Melbourne
EEA (2019) The European environment - state and outlook 2020: knowledge for transition to a sustainable Europe. Luxemburg Publication Office of the European Union, Luxemburg

Fazey I, Bunse L, Msika J et al (2014) Evaluating knowledge exchange in interdisciplinary and multi-stakeholder research. Glob Environ Chang. https://doi.org/ 10.1016/j.gloenvcha.2013.12.012

Feagan M, Matsler M, Meerow S, et al (2019) Redesigning knowledge systems for urban resilience. Environ Sci Policy 101:358-363. https://doi.org/10.1016/j. envsci.2019.07.014

Foss NJ (2007) The emerging knowledge governance approach: challenges and characteristics. Organization 14:29-52

Foss NJ, Michailova S (2009) Knowledge governance. Oxford University Press, New York

Gómez-Baggethun E, Corbera E, Reyes-García V (2013) Traditional ecological knowledge and global environmental change: research findings and policy implications. Ecol Soc. https://doi.org/10.5751/ES-06288180472

Holmes J, Clark R (2008) Enhancing the use of science in environmental policy-making and regulation. Environ Sci Pol. https://doi.org/10.1016/j.envsci.2008.08.004

Hulme M (2009) Why we disagree about climate change: understanding controversy, inaction and opportunity. Cambridge University Press, Cambridge

Jasanoff S (1996) Beyond epistemology: relativism and engagement in the politics of science. Soc Stud Sci. https://doi.org/10.1177/030631296026002008

Juhász S, Lengyel B (2018) Creation and persistence of ties in cluster knowledge networks. J Econ Geogr. https:// doi.org/10.1093/jeg/lbx039

Jull J, Giles A, Graham ID (2017) Community-based participatory research and integrated knowledge translation: advancing the co-creation of knowledge. Implement Sci. https://doi.org/10.1186/s13012-0170696-3

Kemp R, Parto S, Gibson RB (2005) Governance for sustainable development: moving from theory to practice. Int J Sustain Dev. https://doi.org/10.1504/ ijsd.2005.007372

Kraft ME (2017) Environmental policy and politics, 7th edn. Routledge, New York, USA

McIntyre L (2018) Post-truth. MIT Press, Cambridge, MA

McNie EC (2007) Reconciling the supply of scientific information with user demands: an analysis of the problem and review of the literature. Environ Sci Pol. https://doi.org/10.1016/j.envsci.2006.10.004

Menny M, Voytenko Palgan Y, McCormick K (2018) Urban living labs and the role of users in co-creation. GAIA 27:68-77. https://doi.org/10.14512/gaia.27. $\mathrm{S} 1.14$

Meyer M (2010) The rise of the knowledge broker. Sci Commun. https://doi.org/10.1177/1075547009359797

Michaels S (2005) Implementing and sustaining systematic approaches to improving the science-policy interface in 
selected science-based organizations. Environment Canada, Ottawa, Ontario

Michaels S (2009) Matching knowledge brokering strategies to environmental policy problems and settings. Environ Sci Pol. https://doi.org/10.1016/j. envsci.2009.05.002

Mourato J, Schmidt L, Ferrão J, Bussler A (2018) Reframing adaptation to climate change in Portugal: the case of ClimAdaPT. Local. In: Changing societies: legacies and challenges. Vol. iii. The diverse worlds of sustainability. Imprensa de Ciências Sociais, Lisbon, pp 153-177

Ostrom E (2010) Polycentric systems for coping with collective action and global environmental change. Glob Environ Chang. https://doi.org/10.1016/j. gloenvcha.2010.07.004

Porter JJ, Demeritt D, Dessai S (2015) The right stuff? Informing adaptation to climate change in British Local Government. Glob Environ Chang. https://doi. org/10.1016/j.gloenvcha.2015.10.004

Quay R (2010) Anticipatory governance. J Am Plan Assoc. https://doi.org/10.1080/01944363.2010.508428

Rathwell KJ, Armitage D, Berkes F (2015) Bridging knowledge systems to enhance governance of the environmental commons: a typology of settings. Int J Commons. https://doi.org/10.18352/ijc.584

Reinecke S (2015) Knowledge brokerage designs and practices in four european climate services: a role model for biodiversity policies? Environ Sci Pol. https://doi.org/10.1016/j.envsci.2015.08.007

Riedlinger D, Berkes F (2001) Contributions of traditional knowledge to understanding climate change in the Canadian Arctic. Polar Rec (Gr Brit). https://doi.org/ $10.1017 / \mathrm{S} 0032247400017058$

Sarewitz D (2004) How science makes environmental controversies worse. Environ Sci Pol. https://doi.org/ 10.1016/j.envsci.2004.06.001

SDG Knowledge Platform SUSTAINABLE DEVELOPMENT GOAL 17. https://sustainabledevelopment.un. org/sdg17. Accessed 10 May 2020

Sheate WR, Partidário MR (2010) Strategic approaches and assessment techniques-potential for knowledge brokerage towards sustainability. Environ Impact Assess Rev. https://doi.org/10.1016/j.eiar.2009.10.003
Shiroyama H, Yarime M, Matsuo M et al (2012) Governance for sustainability: knowledge integration and multi-actor dimensions in risk management. Sustain Sci. https://doi.org/10.1007/s11625-011-0155-z

Stovel K, Golub B, Meyersson Milgrom EM (2011) Stabilizing brokerage. Proc Natl Acad Sci U S A 108:2132621332

Tàbara JD, Chabay I (2013) Coupling Human Information and Knowledge Systems with social-ecological systems change: reframing research, education, and policy for sustainability. Environ Sci Pol. https://doi.org/ 10.1016/j.envsci.2012.11.005

Tengö M, Brondizio ES, Elmqvist $T$ et al (2014) Connecting diverse knowledge systems for enhanced ecosystem governance: the multiple evidence base approach. Ambio 43:579-591

Tengö M, Hill R, Malmer P et al (2017) Weaving knowledge systems in IPBES, CBD and beyond - lessons learned for sustainability. Curr Opin Environ Sustain 26-27:17-25

UNDP (2014) UNDP knowledge management strategy framework 2014-2017. United Nations General Assembly, New York

van den Hove S (2007) A rationale for science-policy interfaces. Futures. https://doi.org/10.1016/j. futures.2006.12.004

Van Lange PAM, Joireman J, Milinski M (2018) Climate change: what psychology can offer in terms of insights and solutions. Curr Dir Psychol Sci. https://doi.org/ $10.1177 / 0963721417753945$

Ward V, House A, Hamer S (2009) Knowledge brokering: the missing link in the evidence to action chain? Evid Policy 5:267-279. https://doi.org/10.1332/ 174426409X463811

Wasserman S, Faust K (1994) Social network analysis. Cambridge University Press, Cambridge

WCED (1987) Report of the world commission on environment and development: our common future. Oxford University Press, Oxford

Weiss K, Hamann M, Marsh H (2013) Bridging knowledges: understanding and applying indigenous and western scientific knowledge for marine wildlife management. Soc Nat Resour 26:1-18. https://doi.org/ 10.1080/08941920.2012.690065 